\title{
Combined Detrusor and External Urethral Sphincter BTX-A Injections for Detrusor Overactivity and Detrusor External Sphincter Dyssynergia Secondary to Spinal Cord Injury
}

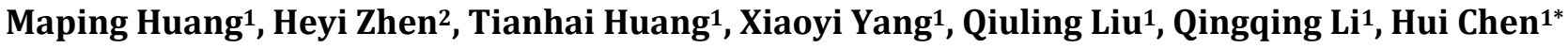 \\ ${ }^{1}$ Department of Urology, Guangdong Provincial Work Injury Rehabilitation Hospital, Guangzhou, China \\ ${ }^{2}$ Department of Traumatic Brain Injury Rehabilitation, Guangdong Province Work Injury Rehabilitation Hospital, \\ Guangzhou, China \\ Email: *doc.chenhui @163.com
}

How to cite this paper: Huang, M.P., Zhen, H.Y., Huang, T.H., Yang, X.Y., Liu, Q.L., Li, Q.Q. and Chen, H. (2021) Combined Detrusor and External Urethral Sphincter BTX-A Injections for Detrusor Overactivity and Detrusor External Sphincter Dyssynergia Secondary to Spinal Cord Injury. Open Journal of Urology, 11, 45-51. https://doi.org/10.4236/oju.2021.112006

Received: September 14, 2020

Accepted: February 23, 2021

Published: February 26, 2021

Copyright $\odot 2021$ by author(s) and Scientific Research Publishing Inc. This work is licensed under the Creative Commons Attribution International License (CC BY 4.0).

http://creativecommons.org/licenses/by/4.0/

(c) (i) Open Access

\begin{abstract}
Objective: To evaluate the efficacy and safety of Combined detrusor and external urethral sphincter BTX-A injections for detrusor overactivity (DO) and detrusor external sphincter dyssynergia (DESD) secondary to spinal cord injury. Study Design: Prospective study. Methods: The study was carried out in 18 SCI patients with detrusor overactivity (DO) and detrusor external sphincter dyssynergia (DESD) receiving Combined detrusor and external urethral sphincter BTX-A injections treatment. Contain $200 \mathrm{U}$ botulinum toxin intradetrusor and $100 \mathrm{U}$ external urethral sphincter injections. The effective outcomes included maximum detrusor pressure at first DO and DESD (PdetmaxDO-DESD), volume at first DO and DESD (VDO-DESD), maximum urethral closure pressure (MUCP), and Incontinence-Specific Quality-of-Life Instrument (I-QoL). Adverse events were recorded. Results: All patients experienced a significant mean reduction in PdetmaxDO-DESD (50.75\%), maximum urethral closure pressure (26.34\%) and a significant mean increase in VDO-DESD $(63.00 \%)$ 12-weeks post-injection. Significant $(\mathrm{p}<0.001) \mathrm{im}-$ provement in mean Incontinence-Specific Quality-of-Life Instrument was also found. No obvious adverse event and toxic effect was observed. Conclusion: Combined detrusor and external urethral sphincter BTX-A injections is a good choice for patients with DO and DESD secondary to spinal cord injury. It could not only protect the upper urinary tract but also improve quality of life.
\end{abstract}

\section{Keywords}

Detrusor Overactivity, Detrusor External Sphincter Dyssynergia, BTX-A, 
Spinal Cord Injury

\section{Introduction}

In patients with neurologic disorders, a major health problem is represented by bladder dysfunction associated with detrusor overactivity (DO), which constantly impairs quality of life (QoL) and often poses a threat for the upper urinary tract (UUT) [1]. Detrusor sphincter dyssynergia (DSD) most often occurs in patients with suprasacral spinal cord injuries or lesions (e.g., MS). Similar to NDO, patients often experience urinary urgency, frequency, nocturia, and incontinence as well as urinary retention and obstructive voiding symptoms [2]. In 2000, Stohrer and Schurch were the first to report the value of intradetrusor injections of botulinum toxin A (BTXA) as a treatment of NDO secondary to SCI refractory to anticholinergic treatment [3]. Since then, numerous studies have further evaluated the efficacy and safety of BTXA and clarified its indications, mainly in patients with SCI, MS or sometimes other conditions such as myelomeningocele or myelitis [4]. In recent years, BTX-A injection has been widely used in the treatment and research of lower urinary tract dysfunction [5]. The site of BTX-A injection is classified into simple detrusor injection for detrusor overactivity or simple sphincter injection, but few study about detrusor-sphincter combined injection for sphincter spasm or detrusor sphincter dysfunction. The aim of this study was evaluate the effect of combined detrusor and external urethral sphincter BTX-A injections in patients with DO and DESD secondary to SCI.

\section{Material and Methods}

From January 2018 to May 2020 a total of 18 patiens whose urodynamic result reveal detrusor overactivity (DO) and detrusor external sphincter dyssynergia (DESD) receiving Combined detrusor and external urethral sphincter BTX-A injections were included in this study. All eligible inpatients over 18 years of age with chronic SCI (i.e. no progression in neurological symptoms in the previous 3 months) were screened for enrolment. Inclusion criteria were: 1) presence of DO and DESD; and 2) inadequate response or intolerance to oral anti-muscarinic agent (oxybutynin, trospium, tolterodine, propiverine, darifenacin and solifenacin) or spasmolytic agents (hyoscine butylbromide), skeletal muscle relaxant (baclofen) and alpha blockers (doxazosin mesylate and terazosin). Exclusion criteria were: 1) allergy to BTX-A; 2) coagulopathy disease and myasthenia gravis; 3 ) acute urinary tract infection; 4 ) other causes of bladder outlet obstruction (i.e. Urethral stricture and benign prostatic hyperplasia); and 5) previous sphincterotomy.

Before treatment, all patients underwent urodynamic examination according to the International Continence Society standard, and maximum detrusor pres- 
sure at first DO and DESD (PdetmaxDO-DESD), volume at first DO and DESD (VDO-DESD), maximum urethral closure pressure (MUCP) were recorded as baseline evaluation, at week 12 after injection, we reevaluate them. The Incontinence-Specific Quality-of-Life Instrument (I-QoL), Voiding volume, urinary incontinence (UI) episodes and Complete dryness were determined from 7 consecutive days of the patient's bladder diary. Voiding volume is defined as voided volume by clean intermittent catheterization (CIC) plus spontaneous voids. Complete dryness is defined as less than one incontinence episode per 24 h.

Injections were performed in the operating room with no anaesthesia or under epidural anaesthesia. The bladder was filled with 100 - $150 \mathrm{ml}$ sterile saline to achieve adequate visualization so as to avoid blood vessels during injections. A 23-gauge needle (Cook Urological Incorporated, Bloomington, IN, USA) was used for injections through a $21 \mathrm{~F}$ rigid cystoscope (Ackermann, Schaffhausen, Switzerland), to a depth of approximately $2 \mathrm{~mm}$ into the detrusor. Firstly, $200 \mathrm{U}$ Botox? vials (100 U each) were reconstituted in $30 \mathrm{ml}$ sterile saline $(6.7 \mathrm{U} / \mathrm{ml})$ and administered in 30 injections of $1 \mathrm{ml}$ each, spaced $1 \mathrm{~cm}$ apart across the detrusor, and additional $41-\mathrm{ml}$ (total $100 \mathrm{U}$ ) BTX-A injections into the external urethral sphincter to a depth of approximately $1 \mathrm{~cm}$ at 3,6, 9 and 12 o'clock positions in approximately equal aliquots. A 16 Foley catheter was inserted into the bladder and kept for 3 - 5 days. Oral prophylactic antibiotics (except aminoglycosides) were administered on the day of treatment.

Student's paired samples t-test was used as appropriate to compare PdetmaxDO-DESD, VDO-DESD, MUCP and I-QoL, of pre-injection and post-injection. The results are shown as mean values and standard deviation (SD). All statistical tests were 2 -sided, and a p-value of 0.05 or less was considered statistically significant. Statistical analyses were performed with SPSS 13.0 software (SPSS Inc., Chicago, IL, USA).

\section{Results}

A total of 18 patients included in our study, the mean age was 27.78 years, mean injury duration 34.28 months (Table 1). The distribution of SCI levels was 13 (72\%) cervical and 5 (28\%) thoracic. The distribution of the American Spinal Injury Association Impairment Scale (AIS) scores was: 12 (66.7\%) Grade A, 4 (22.2\%) Grade B, and 2 (11.1\%) Grade C.

Table 2 shows that the significant difference resulted from preinjection and post-injection PdetmaxDO-DESD, VDO-DESD and MUCP (all p-value < 0.05). Comparing the urodynamic parameters at baseline, all patients experienced a significant mean reduction in PdetmaxDO-DESD (50.75\%), maximum urethral closure pressure (26.34\%) and a significant mean increase in VDO-DESD (63.00\%) at 12 weeks, respectively (Figure 1).

Significant improvement in mean I-QoL, voiding volume, UI episodes and complete dryness were present at week 12 (Table 3 ). 


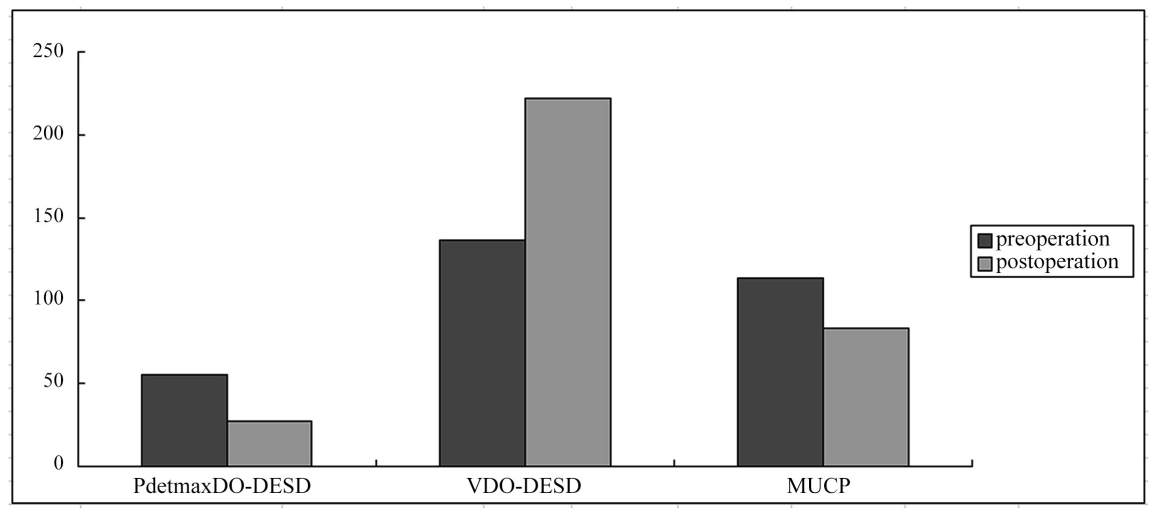

Figure 1. The urodynamic parameters of patients at baseline and at 12-weeks followup. PdetmaxDO-DESD: maximum detrusor pressure at first DO and DESD, VDO-DESD: volume at first DO and DESD, MUCP: maximum urethral closure pressure.

Table 1. Demographic characteristics of the participants.

\begin{tabular}{cc}
\hline Number of patients & 18 \\
\hline Age, years, mean (SD) & $27.78 \pm 7.647$ \\
Injury duration, months, mean (SD) & $34.28 \pm 2.327$ \\
Neurological injury level, n (\%) & \\
Cervical & $13(72 \%)$ \\
Thoracic & $5(28 \%)$ \\
AIS, n (\%) & \\
Grade A & $12(66.7 \%)$ \\
Grade B & $4(22.2 \%)$ \\
Grade C & $2(11.1 \%)$
\end{tabular}

AIS = American Spinal Injury Association Impairment Scale (AIS).

Table 2. The urodynamic parameters of patients at baseline and at 12-weeks followup.

\begin{tabular}{cccc}
\hline & Baseline & $\begin{array}{c}\text { Postoperation } \\
(12 \text {-weeks followup })\end{array}$ & p-value \\
\hline PdetmaxDO-DESD & $55.17 \pm 5.044$ & $27.17 \pm 2.449$ & $<0.05$ \\
VDO-DESD & $136.33 \pm 18.372$ & $222.22 \pm 12.225$ & $<0.05$ \\
MUCP & $113.5 \pm 4.014$ & $83.6 \pm 3.302$ & $<0.05$ \\
\hline
\end{tabular}

PdetmaxDO-DESD: maximum detrusor pressure at first DO and DESD, VDO-DESD: volume at first DO and DESD, MUCP: maximum urethral closure pressure.

Table 3. Baseline and change from baseline in I-QoL, UI episodes, complete dryness and voiding volume.

\begin{tabular}{cccc}
\hline & Baseline & Week4 & Week12 \\
\hline I-QoL & 32.11 & 50.23 & 61.75 \\
voiding volume & 185.68 & 243.75 & 286.97 \\
UI episodes & 11.54 & 9.33 & 5.12 \\
complete dryness & 2 & 5 & 8 \\
\hline
\end{tabular}

$\mathrm{I}$-QoL = Incontinence-Specific-Quality-of-Life Instrument, UI = urinary incontinence. 


\section{Discussion}

Spinal cord injury (SCI) is a significant cause of morbidity and mortality in developing countries, with the worldwide incidence of SCI reported in the literature ranges from 12.1 to 57.8 per million [7]. In chronic SCI patients, the main problems of neurogenic lower urinary tract dysfunction (NLUTD) are failure to store due to detrusor overactivity (DO), or urethral incompetence. Another problem is failure to empty due to detrusor areflexia, bladder neck dysfunction, or detrusor sphincter dyssynergia (DSD), and a usually-combined failure to store and empty, such as due to DSD or DO and impaired contractility [8]. If not well managed, high intravesical pressure may damage the upper urinary tract, causing renal scarring and chronic renal insufficiency, which greatly impairs the quality of life [1]. The application of BoNT-A in urology started from urethral sphincter injections for the treatment of DSD in patients with SCI and MS [6]. After that, the treatment was extended to treat DO and urinary incontinence in NVD and NNVD patients [9] [10]. Double-blind placebo-controlled studies of therapeutic efficacy of BoNT-A urethral sphincter injection have also confirmed the validity and durability of this treatment in patients with SCI and DSD [9] [11].

According to our study, after treatment the patients had a significant decrease in PdetmaxDO-DESD (50.75\%), maximum urethral closure pressure (26.34\%) and a significant mean increase in VDO-DESD (63.00\%) 12 weeks post-injection. Since 2000, minimally invasive BoNT-A injections into the detrusor have been reported to improve clinical and urodynamic parameters and quality of life in patients with refractory NDO in several open-label studies [12] [13] [14] [15]. The high bladder pressure in SCI patients with DO and DESD is probably connected not only to involuntary detrusor contractions, but also to spontaneous obstruction of the outlet. Significantly reduce urethral pressure Combined detrusor and urethral external sphincter BTX-A injections would help to relieve the spontaneous obstruction of the outlet, which might have a certain effect on reducing bladder pressure, besides relieve the symptoms of autonomic dysreflexia $(\mathrm{AD})$ in with neurological level above thoracic 6. Some studies also have reported that BTX-A injection in the external urethral sphincter could restore bladder emptying and reduce detrusor pressure [16] [17]. The dosage of BTX-A we inject to urethra is small, which would not cause stress urinary incotinence. Smith et al. reported that only one female patient developed stress urinary incontinence among 68 patients who received intramuscular injection of external urethral sphincter [18].

Combined detrusor and urethral external sphincter BTX-A injections also improved the quality of life of these patients, which is another important point in the treatment of neurogenic lower urinary tract dysfunction [19]. The reasons we propose for this were that the patients showed greater improvement in voiding volume and 8 patients developed complete dryness than those at baseline, besides most of the patients experienced significant decreases in the symptoms 
of autonomic dysreflexia (AD).

According to the follow-up results, except for slight hematuria, there was no obvious discomfort and postoperative complications

\section{Conclusion}

Combined detrusor and external urethral sphincter BTX-A injections is a good choice for patients with DO and DESD secondary to spinal cord injury. It could not only protect the upper urinary tract but also improve quality of life.

\section{Funding}

This study was supported by: Medical Scientific Research Foundation of Guangdong Province, China (grant number A2018503); Traditional Chinese Medicine of Guangdong Province, China (grant number 20212034 and 20211060); The Science and Technology Project of Guangzhou, China (grant number 201904010256).

\section{Conflicts of Interest}

The authors declare no conflicts of interest regarding the publication of this paper.

\section{References}

[1] Patki, P.S., Hamid, R.H., Arumugam, K., et al. (2006) Botulinum Toxin-Type A in the Treatment of Drug-Resistant Neurogenic Detrusor Overactivity Secondary to Traumatic Spinal Cord Injury. BJU International, 98, 77-82. https://doi.org/10.1111/j.1464-410X.2006.06192.x

[2] Stofell, J.T. (2016) Detrusor Sphincter Dyssynergia: A Review of Physiology, Diagnosis and Treatment Strategies. Translational Andrology and Urology, 5, 127-135.

[3] Schurch, B., Schmid, D.M. and Stohrer, M. (2000) Treatment of Neurogenic Incontinence with Botulinum Toxin A. The New England Journal of Medicine, 342, 665. https://doi.org/10.1056/NEJM200003023420918

[4] Apostolidis, A., Dasgupta, P., Denys, P., Elneil, S., Fowler, C.J., Giannantoni, A., et al. (2009) Recommendations on the Use of Botulinum Toxin in the Treatment of Lower Urinary Tract Disorders and Pelvic Floor Dysfunctions: A European Consensus Report. European Urology, 55, 100-119. https://doi.org/10.1016/j.eururo.2008.09.009

[5] Jhang, J.F. and Kuo, H.C. (2016) Botulinum Toxin A and Lower Urinary Tract Dysfunction: Pathophysiology and Mechanisms of Action. Toxins (BaseI), 8, 120-131. https://doi.org/10.3390/toxins8040120

[6] Dykstra, D.D. and Sidi, A.A. (1990) Treatment of Detrusor-Sphincter Dyssynergia with Botulinum Atoxin: A Double-Blind Study. Archives of Physical Medicine and Rehabilitation, 71, 24-26.

[7] Van den Berg, M.E., Castellote, J.M., Mahillo-Fernandez, I. and de Pedro-Cuesta, J. (2010) Incidence of Spinal Cord Injury Worldwide: A Systematic Review. Neuroepidemiology, 34, 184-192. https://doi.org/10.1159/000279335

[8] Kuo, H.C. (1998) Quality of Life after Active Urological Management of Chronic Spinal Cord Injury in Eastern Taiwan. European Urology, 34, 37-46. https://doi.org/10.1159/000019676 
[9] Kuo, H.C. (2003) Botulinum A Toxin Urethral Injection for the Treatment of Lower Urinary Tract Dysfunction. The Journal of Urology, 170, 1908-1912. https://doi.org/10.1097/01.ju.0000091281.50081.f0

[10] Smith, C.P. and Chancellor, M.B. (2004) Emerging Role of Botulinum Toxin in the Treatment of Voiding Dysfunction. The Journal of Urology, 171, 2128-2137. https://doi.org/10.1097/01.ju.0000127725.48479.89

[11] De Seze, M., Petit, H., Gallien, P., de Seze, M.P., Joseph, P.A., Mazaux, J.M. and Barat, M. (2002) Botulinum a Toxin and Detrusor Sphincter Dyssynergia: A DoubleBlind Lidocaine-Controlled Study in 13 Patients with Spinal Cord Disease. European Urology, 42, 56-62. https://doi.org/10.1016/S0302-2838(02)00209-9

[12] Schurch, B., Stohrer, M., Kramer, G., Schmid, D.M., Gaul, G. and Hauri, D. (2000) Botulinum-A Toxin for Treating Detrusor Hyperreflexia in Spinal Cord Injured Patients: A New Alternative to Anticholinergic Drugs? Preliminary Results. The Journal of Urology, 164, 692-697. https://doi.org/10.1016/S0022-5347(05)67283-7

[13] Karsenty, G., Denys, P., Amarenco, G., de Seze, M., Game, X., Haab, F., Kerdraon, J., Perrouin-Verbe, B., Ruffion, A., Saussine, C., et al. (2008) Botulinum Toxin A (Botox) Intradetrusor Injections in Adults with Neurogenic Detrusor Overactivity/ Neurogenic Overactive Bladder: A Systematic Literature Review. European Urology, 53, 275-287. https://doi.org/10.1016/j.eururo.2007.10.013

[14] Mangera, A., Andersson, K.E., Apostolidis, A., Chapple, C., Dasgupta, P., Giannantoni, A., Gravas, S. and Madersbacher, S. (2011) Contemporary Management of Lower Urinary Tract Disease with Botulinum Toxin A: A Systematic Review of Botox (Onabotulinumtoxin A) and Dysport (Abobotulinumtoxin A). European Urology, 60, 784-795. https://doi.org/10.1016/j.eururo.2011.07.001

[15] Stoehrer, M., Wolff, A., Kramer, G., Steiner, R., Lmochner-Ernst, D., Leuth, D. Steude, U. and Ruebben, H. (2009) Treatment of Neurogenic Detrusor Overactivity with Botulinum Toxin A: The First Seven Years. Urologia Internationalis, 83, 379 385. https://doi.org/10.1159/000251175

[16] Kuo, H.C. (2008) Therapeutic Satisfaction and Dissatisfaction in Patients with Spinal Cord Lesions and Detrusor Sphincter Dyssynergia Who Received Detrusor Botulinum Toxin a Injection. Urology, 72, 1056-1060.

https://doi.org/10.1016/j.urology.2008.04.026

[17] Chen, S.L., Bih, L.I., Huang, Y.H., Tsai, S.J., Lin, T.B. and Kao, Y.L. (2008) Effect of Single Botulinum Toxin A Injection to the External Urethral Sphincter for Treating Detrusor External Sphincter Dyssynergia in Spinal Cord Injury. Journal of Rehabilitation Medicine, 40, 744-748. https://doi.org/10.2340/16501977-0255

[18] Smith, C.P., Nishiguchi, J., O’Leary, M., et al. (2005) Single-Institution Experience in 110 Patients with Botulinum Toxin A Injection into Bladder or Urethra. Urology, 65, 37-41.

[19] Groen, J., Pannek, J., Castro Diaz, D., Del Popolo, G., Gross, T., Hamid, R., et al. (2016) Summary of European Association of Urology (EAU) Guidelines on Neuro-Urology. European Urology, 69, 324-333. https://doi.org/10.1016/j.eururo.2015.07.071 